Historia y comunicación social

ISSN-e 1988-3056

https://dx.doi.org/10.5209/hics.66300

\title{
El negocio de las noticias falsas. El caso de El Mundo Today
}

\author{
María José Ufarte Ruiz; ; Pavel Sidorenko Bautista²; Juan Ignacio Cantero de Julián ${ }^{3}$
}

Recibido: 25 de febrero de 2019. / Aceptado: 26 de septiembre de 2019.

Resumen. La finalidad de esta investigación es analizar la estructura, composición y funcionamiento de El Mundo Today, así como sus procesos productivos y el impacto de su actividad para la empresa. Para alcanzar este objetivo se utilizará una metodología mixta, con procedimientos de tipo cuantitativo, como el cuestionario, y cualitativo, como las entrevistas semiestructuradas en profundidad y la observación no participante, que se aplicará sobre este diario. Se trata de una triangulación de técnicas que permitirá extraer conclusiones y aportar ejemplos de interés a la investigación. Los resultados revelan que este proyecto nació como una startup, aunque rápidamente se consolidó como empresa independiente, sostenible y rentable, que ha encontrado diferentes vías de ingresos y cuenta con equipos de trabajo multidisciplinares.

Palabras clave: Noticias falsas; Modelo de Negocio; Sátira; Periodismo.

\section{[en] The business of false news. The case of El Mundo Today}

Abstract. The purpose of this research is to analyze the structure, composition and functioning of $E l$ Mundo Today, as well as its production processes and the impact of its activity for the company. To achieve this objective, a mixed methodology will be used, with procedures of quantitative type, such as the questionnaire, and qualitative, such as semi-structured in-depth interviews and non-participant observation, which will be applied to this journal. It is a triangulation of techniques that will make it possible to draw conclusions and provide examples of interest to the investigation. The results reveal that this project was born as a startup, although it quickly consolidated itself as an independent, sustainable and profitable company, which has found different income channels and has multidisciplinary work teams. Keywords: Fake news, Business Model; Satire; Journalism.

Sumario: 1. Introducción; 2. Estado de la cuestión; 2.1. Las startups: entre el emprendimiento y el autoempleo. 3. Metodología; 4. Resultados; 4.1. Estrucutura, organización y funcionamiento; 4.2. Metodologías y procesos productivos; 4.3. Modelo de negocio; 5 . Discusión y conclusiones; 6 . Referencias.

Cómo citar: Ufarte Ruiz, M. J.; Sidorenko Bautista, P.; Cantero de Julián, J. I. (2019). El negocio de las noticias falsas. El caso de El Mundo Today, en Historia y comunicación social 24 (2), 561-578.

\footnotetext{
1 Universidad de Castilla-La Mancha. mariajose.ufarte@uclm.es

2 Universidad de Castilla-La Mancha pavel.sidorenko@alu.uclm.es

3 Universidad de Castilla-La Mancha. juanignacio.cantero@alu.uclm
} 


\section{Introducción}

La difusión de informaciones falsas e imprecisas está en auge, a pesar de no constituir una característica propia y exclusiva del momento actual (Burkhardt, 2017, Wilkilson, 2017). En los últimos años, las webs y publicaciones impresas dedicadas a los textos distorsionados (Khaldarova; Pantti, 2016), con altos niveles de facticidad (Tandoc; Lim, Ling, 2018), que se modifican, se ridiculizan y se someten a nuevas interpretaciones (Balmas, 2012), se han disparado a nivel nacional e internacional, aprovechando la transformación radical de la industria mediática protagonizada por el avance de las nuevas tecnologías digitales (Boczkowski, 2004; Pavlik, 2015). Tal ha sido el auge de estas historias falsas que parecen ser noticias, se difunden a través de internet u otros medios, y han sido creadas normalmente para influir políticamente o como broma (Cambridge Dictionary, 2018; Collins Dictionary, 2018), que ya se establecen diferentes tipologías.

Rubin, Chen y Conroy (2015) distinguen tres modalidades. La primera son las noticias elaboradas por la prensa sensacionalista, que cuentan con titulares no contrastados y exageraciones, y están dirigidas a capturar la atención del público para intentar cazar a grandes masas de audiencia a través de internet. La segunda son los bulos a gran escala que se han construido de forma deliberada para engañar a la audiencia, y que se elaboran siguiendo los preceptos de las noticias tradicionales, por lo que consiguen enmascarar su intención real de desinformación y ser concebidas como verídicas. Y la tercera y última modalidad son las noticias falsas humorísticas, que no pretenden crear confusión en la audiencia sino apelar a su sentido del humor.

Por su parte, Tandoc, Lim y Ling (2018) diferencian seis categorías: 1) Noticias satíricas, que es la fórmula más común para la presentación de las noticias falsas y está basada en el empleo del humor y la exageración para trasladar la información a la audiencia. 2) Parodias, que aunque comparten algunas características con las noticias satíricas, se diferencian de estas en que no hacen referencia a contenidos de actualidad, sino que se trata de elementos totalmente ficticios construidos expresamente para la ocasión. 3) Construcción de noticias, que hace referencia a aquellos contenidos publicados al estilo de la información elaborada por los medios, pero en los que la audiencia no es advertida de que está ante contenidos falsos, por lo que se incurre en la desinformación. 4) Manipulación de imágenes, basada en la creación de falsas narrativas derivadas de la modificación de fotografías o vídeos. 5) Publicidad, basada en la difusión de contenidos publicitarios bajo la apariencia de informes. 6) Propaganda, que son historias que se asemejan a las noticias creadas por una organización política con el objetivo de influir en la percepción que la ciudadanía tiene de la misma o de alguno de sus integrantes.

A partir de estas clasificaciones vemos, pues, que las noticias basadas en el humor, la parodia y la sátira son una modalidad de fake news, a pesar de que la prensa satírica existe desde el siglo XVIII (Checa Godoy, 2010; Laguna, 2003; Laguna, Martínez, 2003; Llera, 2003; Román, 2010). Su objetivo no es crear confusión en la audiencia, sino apelar a su sentido del humor (Rubin; Chen; Conroy, 2015), y a la exageración, para trasladar la información al público (Tandoc; Lim; Ling, 2018), que es consciente de la naturaleza satírica de estos contenidos, aunque su formato y apariencia resultan similares a los textos que se pueden encontrar en cualquier medio de referencia. 
En este contexto, el mercado de la información está poblado de este tipo de publicaciones. En EE.UU., por ejemplo, destaca The Onion (1988), que divulga noticias satíricas de temas internacionales, nacionales y locales. En Latinoamérica, Colombia cuenta con la página Actualidad Panamericana (2014), Venezuela con El Chigüire Bipolar (2008), Chile con The Clinic (1998), y Argentina con la revista Barcelona (2003). En Europa también existen proyectos similares. En Irlanda está Waterford Whispers News (2009), que fue fundado por Colm Williamson, y en Italia, Lercio (2012), creado por Michele Incollu. Alemania dispone del portal Der Postillon (2008), mientras que en Francia destacan Le Gorafi (2012), Le Canard Enchaîné (1915) y el semanario de izquierdas Charlie Hebdo, creado en 1992. En los Países Bajos está De Speld (2007), y en Gran Bretaña, The Daily Mash (2007).

La mayoría de estas iniciativas han tenido trayectorias muy similares: comenzaron aproximadamente hace una década siguiendo el modelo de The Onion, no tienen competencia clara en su mercado y casi todas han llevado su web a otros medios, como los libros, las obras de teatro y los programas de radio y televisión. Sin embargo, también hay diferencias, como en las líneas editoriales y las tendencias políticas (Rubio Hancock, 2018).

Siguiendo la estela internacional, en España hay diez publicaciones dedicadas a este tipo de contenidos. A nivel impreso, hay dos: El Jueves, que es una revista semanal del grupo Zeta, que se edita desde 1977 y está dirigida por Mayte Quílez, y la revista Mongolia, que se publica desde 2012, aunque "todo lo que dice es mentira" y "nada de lo que se dice es verdad", como declara en su portal online. Ambas cuentan con página web. Por su parte, en la red operan las ocho restantes. El Mundo Today (2009) es el más leído en el país y su contenido es totalmente ficticio y humorístico. También están los portales La Gallina Ilustrada (2007), La Gaceta Global (2016) y la web Hay Noticia (2017), que igualmente gestiona las publicaciones satíricas La Voz del Becario (2018) y El Diario Montañoso (2018). Además, hasta enero de 2019, el mercado español también contaba con el portal BuzzFeed España, pero cesó su actividad después de tres años, agudizando la crisis del periodismo digital. Estas propuestas también han servido de estímulo para que se creen en la red iniciativas similares a nivel autonómico. En este sentido, destaca el Errado de Aragón (2015), que publica textos satíricos de los lugares, personajes y situaciones típicamente aragonesas, y el Baifo Ilustrado (2012), que se centra en los contenidos "satíricos, entrañables y tontorrones que se publican en las Islas Canarias", como explican en su web.

La mayoría de estos proyectos ingresan grandes sumas de dinero procedente de estos contenidos (Kirby, 2016; Allcott; Gentzkow, 2017), imitan la apariencia e incluso el nombre de organizaciones informativas consagradas o reconocidas (Boczkowski, 2016), y llegan a alcanzar elevadas cotas de atención (Berinsky, 2015).

La presente investigación se articula a partir de los siguientes objetivos: 1) Analizar la estructura, composición y funcionamiento de El Mundo Today; 2) Estudiar sus procesos productivos para conocer qué herramientas utilizan; 3) Medir el impacto de su actividad para la empresa. El trabajo recurre tanto a la metodología cuantitativa como cualitativa y parte de las siguientes hipótesis:

H1. El diario nació como una startup, pero su rápido crecimiento y elevado número de seguidores y usuarios lo han convertido en una empresa consolidada.

H2. El modelo de negocio de este proyecto es rentable, ya que posee una cartera diversificada de fuentes de financiación que aseguran su sostenibilidad e independencia. 
H3. El objetivo de El Mundo Today no es desinformar, sino entretener y hacer un tipo de humor a través de la sátira sobre la actualidad nacional e internacional que perdure en el tiempo.

Una aproximación exploratoria, obtenida a través de la revisión bibliográfica, permitía sostener que esta iniciativa es un modelo de negocio sostenible, rentable e independiente. Este primer trabajo aspira a asentar el examen con un primer estudio de caso en profundidad. En las siguientes líneas se recoge la literatura científica para entender el contexto, se presenta la metodología y se explican los resultados obtenidos en la presente investigación.

\section{Estado de la cuestión}

La crisis del paradigma mediático industrial ha creado nuevos modelos de negocio (Valero; González, 2018). Una revisión sobre la literatura académica que aborda este concepto constata en primer lugar que existe poca unanimidad en torno al mismo (García Santamaría, 2014), que es tan antiguo como la formulación de la teoría de la gestión, pero que resurge en los últimos quince años ante el cambio que supone la transformación de la sociedad de la información y la irrupción de Internet (Campos, 2010a; Infoadex, 2014). Existen algunas aproximaciones interesantes que se han esbozado estos últimos años, como las de Timmers (1998), Chesbrough y Rosembloom (2001), Osterwalder, Pigneur y Tucci (2005); Navas López y Guerras Martín (2007), Benoît y Lecocq (2009), Giles (2010), Picard (2002, 2010); Faustino y Gonçalez (2011); Goyanes (2013), y Pavlik (2013).

Un modelo de negocio debe describir las bases de cómo una organización crea, proporciona y captura valor (Carvajal, 2015a). Describe, por tanto, los productos y servicios, la propuesta de valor que ofrece a sus clientes y cómo será capaz de generar suficientes ingresos para ser una empresa rentable. Para Picard (2002), pueden ser definidos como la arquitectura del producto, sus servicios y flujos de información, e incluyen una descripción de sus actividades, los beneficios potenciales para los intervinientes y las fuentes de ingresos de las que se nutrirán sus presupuestos. Es un instrumento que responde al cambio para comprender y experimentar las transformaciones que se producen en los sectores en crisis (Benoît; Lecocq, 2009; Campos, 2010b).

Timmers (1998) considera que el modelo de negocio incluye varios aspectos: la descripción de la arquitectura del producto, la especificación de los distintos actores que participan en el negocio y sus roles, y la definición de las fuentes de ingresos. Y Chesbrough y Rosembloom (2001) explican que entre sus funciones destaca la articulación de sus proposiciones de valor, la identificación de un segmento de mercado, la definición de la estructura de la cadena de valor, la estimación de costes y beneficios, la posición de la empresa en la red de valor y la formulación de su estrategia competitiva. En similares términos se expresan Osterwalder, Pigneur y Tucci (2005), que identifican nueve elementos en un modelo de negocio: propuesta de valor, cliente objetivo, canal de distribución, relaciones, configuración de la cadena de valor, competencias esenciales, red de socios, estructura de costes y sistema de ingresos.

García Santamaría (2014) recuerda que desde que comenzó el desarrollo de las ediciones digitales de la prensa se ha producido un elevado grado de experimentación de modelos de ingresos: desde el modelo publicitario - el más extendido- hasta 
el modelo de pago (vía suscripción, vía venta por unidad); el modelo combinado (la edición digital se ofrece con un plus adicional a si solamente se compra la edición impresa) o el modelo de comercio electrónico (el medio recibe una comisión en función del número de usuarios que clica o compra un producto anunciado en la edición digital).

Por su parte, Carvajal (2015b) diferencia seis modelos para el periodismo en la era de las plataformas: 1) Modelo de negocio periodístico tipo plataforma, que consiste en la agregación de una masa crítica de clientes y el diseño de una ingeniería tecnológica que facilite el descubrimiento, la creación del contenido y la interacción de la comunidad; 2) Modelo de negocio de periodismo distribuido nativo, que genera contenidos adaptables e integrados en cada plataforma, red y canal de distribución; 3) Modelo de negocio periodístico de curación, cuyo modelo de ingresos es el uso del patrocinio en newsletters; 4) Modelo de negocio periodístico de tipo viral, que detecta tendencias y responde rápido para editar contenido viralizable; 5) Modelo de negocio periodístico enfocado, que se fundamenta en el periodismo de agenda propia, con una comunidad participativa incentivada por un equipo de redactores y columnistas específicos; y 6) Modelo de negocio periodístico global, que combina las herramientas y las habilidades de los demás modelos. Pero no existen modelos puros, sino que suelen ser el resultado de la combinación de varios sistemas (García Santamaría, 2014; Manfredi; Rojas; Herranz, 2015). Esta hibridación ha creado en la empresa periodística un modelo de negocio mixto, que saca partido de la tecnología sin renunciar a los contenidos y con un ahorro mucho más modesto (Evangelista, 2014; Aguado, 2016).

Por supuesto, hay modelos ajenos o antiguos que aún funcionan. En cualquier caso, se trata de un nuevo escenario de oportunidades que permite poner en práctica iniciativas de autoempleo gracias a las tecnologías digitales, que reducen las barreras de entrada al sector y hacen factible el desarrollo del espíritu emprendedor entre los periodistas como vía alternativa para el ejercicio de la profesión (Casero; Cullell, 2013).

Debido a los distintos aspectos que abarca el concepto de modelo de negocio, en este trabajo se tratan con especial interés los referentes a lo que Timmers (1998) denomina fuentes de ingresos o modelo de ingresos (revenue model).

\subsection{Las startups: entre el emprendimiento y el autoempleo}

El concepto de modelo de negocio está muy ligado al de startup (Valero; González (2018), que es "una institución humana diseñada para crear nuevos productos y servicios bajo condiciones de incertidumbre extrema" (Eric Ries, 2011: 8), y que busca un modelo de negocio nuevo que sea escalable, repetible y rentable (Blank; Dorf, 2012). Estas iniciativas están relacionadas con las tecnologías digitales e Internet (Montoya Pineda, 2016: 144), y se caracterizan por su estructura flexible (Baumann, 2013: 79-80), plantillas poco numerosas e inexistencia de redacciones físicas al uso (Pavlik, 2013; Rosique; Barranquero, 2015), y multidisciplinariedad y complementación entre los perfiles profesionales que las componen (De Lara González, 2015). Es decir, el perfil del periodista se redefine en estas nuevas empresas como una figura flexible con múltiples especializaciones y competencias, y la capacidad de colaborar con perfiles muy diferentes.

La mentalidad abierta y renovada de sus emprendedores (Gynnild, 2013) hace que cree productos innovadores (Carlson; Usher, 2016), por lo que son percibidas 
como una respuesta esperanzadora ante el declive del periodismo tradicional, sus modelos económicos y sus formas comunicativas (García-Avilés et al., 2016; González, 2014; Jarvis, 2015; Manfredi, 2015). Además, una de sus principales ventajas es que no tienen que soportar la estructura de costos y la inmensa infraestructura de los medios establecidos (Küng, 2017: 90).

Una vez establecido el marco teórico, se analiza a continuación el caso de $E l$ Mundo Today como modelo de prensa satírica basado en noticias falsas.

\section{Metodología}

Para acotar el objeto de estudio, se analizaron previamente las características y la estructura de los diez proyectos satíricos que hay en España: El Mundo Today, Hay Noticia, La Voz del Becario, El Diario Montañoso, La Gallina Ilustrada, Errado de Aragón, Baifo Ilustrado, La Gaceta Global, El Jueves y Mongolia. Se eligió El Mundo Today como caso de estudio por tratarse del diario satírico en línea más leído en el país, ser uno de los pioneros y haber obtenido diversos galardones, como el Premio Bitácoras, en 2010 y 2011 (categoría Humor), el Premio INTRAS 2015, que reconoce la labor del medio en favor de las personas con enfermedad mental; y el Premio Blasillo de Huesca 2016, que galardona el ingenio español en Internet. Además, desarrolla su labor en el ámbito español y, a corto plazo, ha alcanzado una repercusión notable en el ámbito profesional y social.

La presente investigación se articula a partir de los siguientes objetivos: 1) Analizar su estructura, composición y funcionamiento; 2) Estudiar los procesos productivos para conocer qué herramientas utilizan hasta que una idea se convierte en un texto de su portada online; 3) Medir el impacto de su actividad para la empresa.

La fórmula metodológica empleada para alcanzar estos propósitos ha sido la triangulación metodológica de técnicas cualitativas y cuantitativas (Gaitán; Piñuel, 1998: 286), que, como apuntan Soler y Enríquez (2012: 887), consiste básicamente en contrastar información entre distintas fuentes para obtener una contextualización suficiente de los fenómenos estudiados.

Tras la revisión de la bibliografía, se diseñó una entrevista semiestructurada en profundidad que abordara los asuntos más relevantes sobre el objeto de estudio. Entrevistamos a los dos directores del diario, Xavi Puig Ripoll y Kike García de la Riva, a los que se les preguntó, entre otras cuestiones, por su método de trabajo, las herramientas que usan, la principal fuente de ingresos del medio y las estrategias para fortalecer la comunidad de usuarios. Las entrevistas se realizaron entre enero y febrero de 2019.

En segundo lugar, se ha difundido entre los integrantes del medio un cuestionario online con diez preguntas cerradas y categóricas relacionadas con el objeto de estudio. La recogida de datos se llevó a cabo entre los meses de enero y febrero de 2019. El cuestionario fue cumplimentado de forma anónima por 7 trabajadores (el medio cuenta con un total de 11 trabajadores), de los que 5 son hombres y 2, mujeres. La finalidad de este cuestionario era conocer el perfil de los miembros que integran la plantilla de El Mundo Today, así como la estructura, la composición y el funcionamiento del medio.

Por último, hemos llevamos a cabo una observación no participante durante su proceso de producción. Esta técnica cualitativa se realizó durante el mes de febrero 
de 2018, con el propósito de conocer su proceso productivo y recabar información adicional sobre su metodología de trabajo.

\section{Resultados}

\subsection{Estrucutra, organización y funcionamiento}

El Mundo Today fue fundado en enero de 2009 por Xavi Puig Ripoll y Kike García de la Riva, cuyo objetivo era hacer un informativo de televisión satírico. Desde su puesta en marcha, la web se expande rápidamente, ganando entidad y creciendo como un proyecto fijo de forma independiente. En la actualidad, el medio está compuesto por un total de once personas: los dos directivos más nueve colaboradores: Javier Ramos, Tomás Fuentes, Juan José Ramírez, Fernando Costilla, Biel Perelló, Bárbara Alpuente, Alberto González y Ángela Armero. Por su parte, las gestiones de proyectos y acciones publicitarias son realizadas por Abigail López Enrech. Además, cuenta con un equipo "flotante" del que tirar cuando surgen proyectos más grandes.

Según los datos de la muestra -el 63\% de los integrantes del diario-, la media de edad de los trabajadores es de 38 años; el 72,73\% son hombres y el 27,27\%, mujeres, y llevan trabajando en la empresa un promedio de 7,5 años, aunque cuentan con más de 10 años de experiencia en el sector. Todos poseen una amplia variedad de perfiles: editores de vídeo, guionistas de radio y televisión, desarrollo de audiencias, diseñador de experiencia de usuarios y especialistas en Photoshop. Su formación también es diversa: Los directores han estudiado Filosofía y Comunicación Audiovisual, mientras que el resto de la plantilla son periodistas (40\%), guionistas y realizadores (45\%), o bien poseen otra titulación (15\%). "Es un perfil similar al que encontraríamos en programas de humor en televisión, aunque siendo una plantilla pequeña es esencial ser trabajadores flexibles", explica García de la Riva.

El diario no está dividido en departamentos o secciones, ya que es "demasiado pequeño", según Puig Ripoll, algo que no ha impedido que tenga una gran influencia y alcance y se haya convertido en la web satírica de referencia en España, con una fiel cartera de lectores. El portal, que puede leerse de forma gratuita, ha recibido 1,5 millones de visitas de agosto de 2018 a enero de 2019 , siendo la media mensual de 250.000 visitas, con un porcentaje de rebote del 78,25\% (Gráfico 1). Al hilo de estas cifras, Puig Ripoll recuerda: "Nosotros no vamos hacia los usuarios, sino que es el usuario el que se encuentra con nosotros o nos busca. Cada vez que uno de nuestros chistes se comparte en redes llegamos a nuevo público, pero no depende de nosotros". 


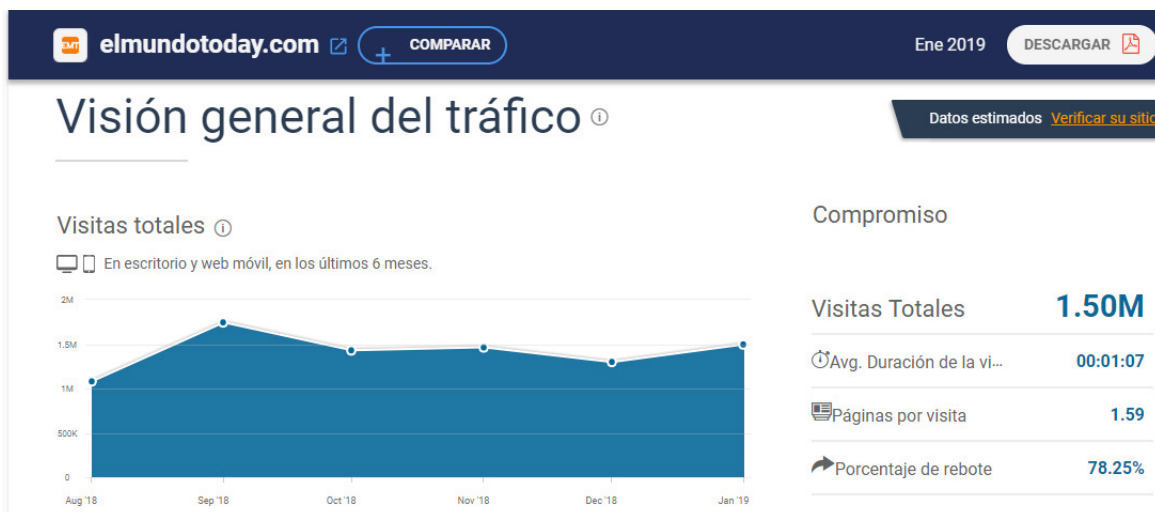

Grafico 1: Número de visitas que ha recibido El Mundo Today de agosto de 2018 a enero de 2019.

Fuente: Similarweb. Website Analysis Overview Report.

Desde el diario reconocen que "no analizan las audiencias", porque "existen pocas estrategias para aumentarlas", por lo que se limitan a "hacer el trabajo lo mejor posible". Tampoco cuentan con ninguna estrategia para fortalecer su comunidad de usuarios. En cuanto a la procedencia de las visitas, la mayoría se producen desde España (74,36\%), seguidas de Argentina (5,31\%); México (3,67\%); Colombia (2,06\%), y Alemania (1,63\%) (Gráfico 2).

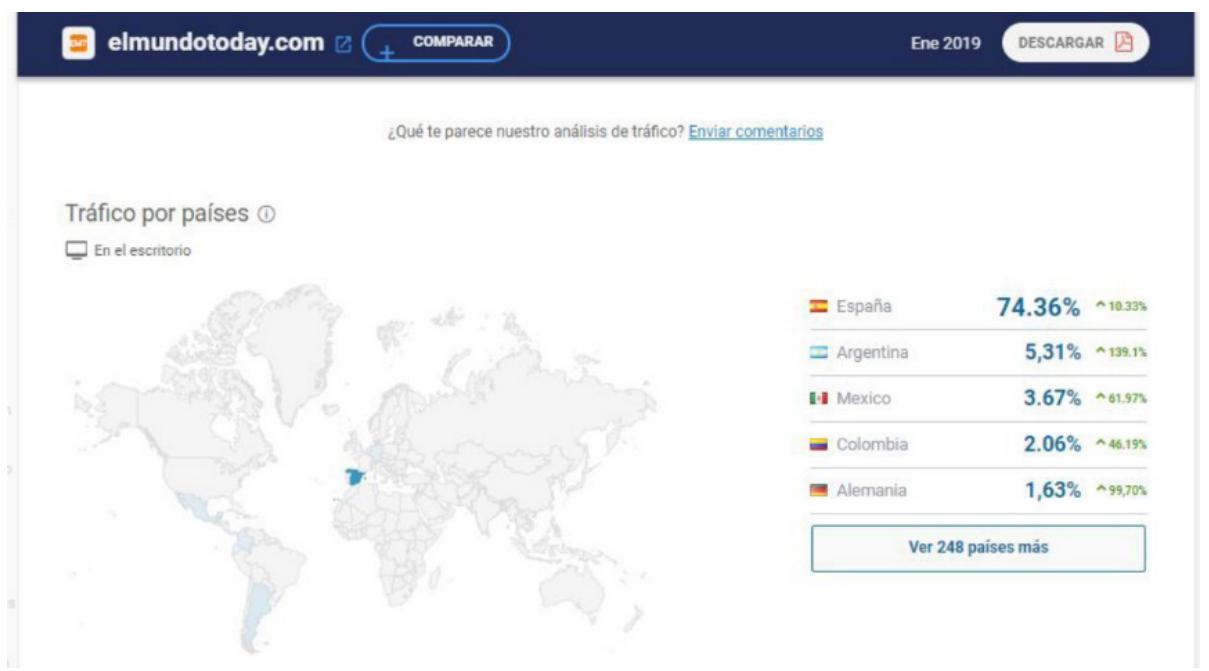

Grafico 2: Visitas por países.

Fuente: Similarweb. Website Analysis Overview Report.

En relación a las vías de acceso, un 43\% lo hace a través de redes sociales, mientras que un $29,86 \%$ ha entrado de forma directa a la web y un $17 \%$ mediante búsquedas orgánicas, es decir, por medio de palabras clave en un motor de búsqueda. Por el contrario, un $8,85 \%$ lo ha hecho a través de referencias, un $0,41 \%$ por correo electrónico y un $0,06 \%$ a través de un monitor (Gráfico 3). 
Fuentes de tráfico (1)

$\square$ En el escritorio

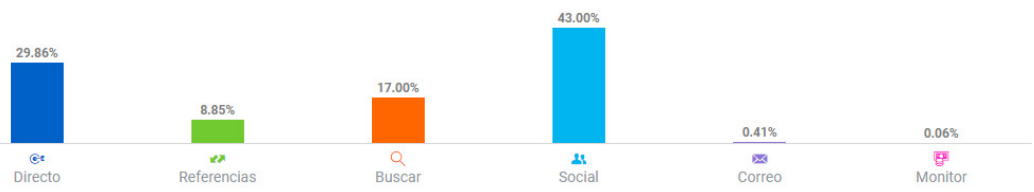

Grafico 3: Vías de acceso a El Mundo Today.

Fuente: Similarweb. Website Analysis Overview Report.

En concreto, Facebook $(61,97 \%)$ ha sido la red social más utilizada, seguida de Twitter $(37,40 \%)$, YouTube $(0,37 \%)$, WhatsApp $(0,15 \%)$, y Netvibes $(0,065)$ (Gráfico 4).
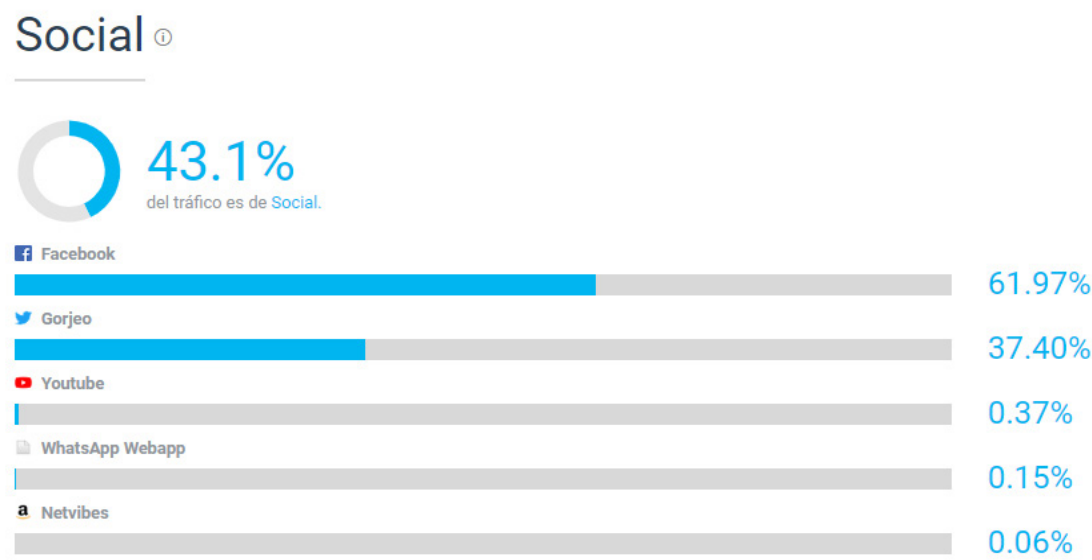

Grafico 4: Redes sociales más utilizadas para acceder al portal.

Fuente: Similarweb. Website Analysis Overview Report.

Los sitios webs de referencia líderes, es decir, los que remiten la mayor parte del tráfico (no pagado) a El Mundo Today son: meneame.net (79,76\%), Feedly.com (7,53\%), Genbeta.com (2,54\%), Huffngtopost.es (2,47\%), y Legorafi.fr (1,90\%). Por su parte, las webs donde se desvía a la gente de El Mundo Today son: emtstatic.com (70,77\%); Facebook (13,01\%), Twitter (4,50\%); YouTube (4,49\%), lallamastore. com /2,56\%) (Gráfico 5). 

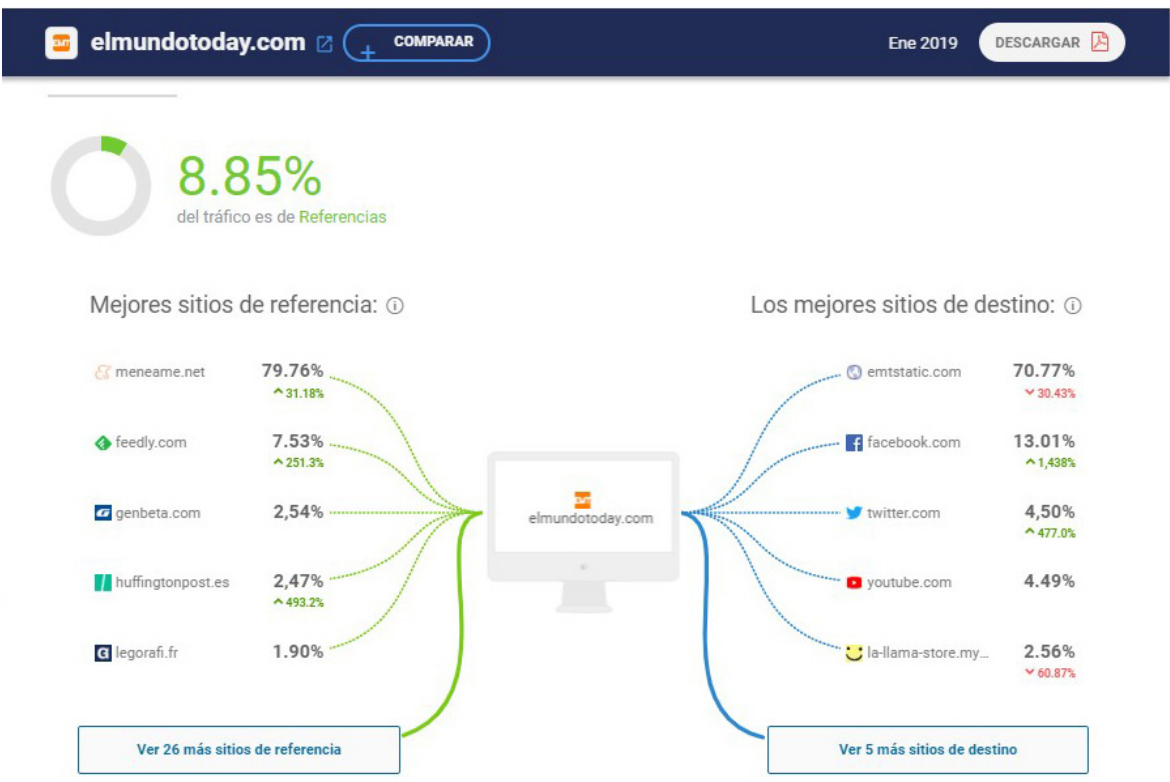

Gráfico 5. Tráfico de referencias y destino.

Fuente: Similarweb. Website Analysis Overview Report.

Las publicaciones "Una anciana invoca al demonio en un curso de inglés", "Telecinco emite por error ocho segundos de un documental" y "Operan a un vasco sin anestesia" han sido las más leídas en la historia del diario, que con frecuencia convierte en virales sus publicaciones. Es el caso, por ejemplo, de la noticia titulada "Empiezan a construir una casa por las banderas del balcón", que fue viral en apenas cinco minutos después de su publicación.

No obstante, el portal también ha recibido diversas coacciones, como las del Partido Popular, que amenazó "con iniciar cuantas acciones legales fueran necesarias" si no cerraban su página satírica "Rajoy presidente", en la que parodiaba su programa político. La coalición consideraba que daba lugar a confusión y podría conculcar el derecho al honor del expresidente, a pesar de estar registrada en el Ministerio de Industria como propiedad de El Mundo Today. El Ayuntamiento de Teruel y la Unión Romaní Española, entre otras instituciones y personalidades, también han amenazado a la web.

Los propietarios, por su parte, también se han quejado de la censura que reciben, a pesar de que su finalidad es "ser lo más entretenidos posibles", reconoce García de la Riva. En este sentido, recuerda que Instagram censuró una de las noticias que publicaron sobre Felipe VI, que se titulaba: "Felipe VI beberá durante todo el día para reunir valor y abdicar esta noche". La pieza tiraba de humor para plantear "una hipótesis muy difícilmente creíble", aunque fue eliminada por no seguir las normas de la red social "en relación con contenido o símbolos que incitan al odio", recuerda.

\subsection{Metodologías y procesos productivos}

El Mundo Today no dispone de oficinas ni de redacción. Las publicaciones se organizan e intercambian a través de un grupo de WhatsApp denominado "El Mundo 
Today Redacción", en el que están presentes los dos directores del medio y cuatro o cinco redactores más, dependiendo del momento. En este grupo se comparten links a la prensa convencional, con la finalidad de fijarse en formatos de textos periodísticos que puedan implementar en el futuro. "El WhatsApp es como un brainstorming perpetuo y continuo en el que cada uno va vertiendo a lo largo del día todo lo que se le ocurre", explica Puig Ripoll. Por su parte, García de la Riva añade que la inspiración también surge cuando hojean un periódico, ven un anuncio, o una foto que les llama la atención, ya que su objetivo principal "no es hacer chistes de la actualidad, sino resultar los más entretenidos posibles siendo fieles a la línea editorial del diario, que es la sátira tradicional, pero también la creación de un universo ficticio".

La producción de contenidos consta de varias fases después de su puesta en común en esta red social. Todos los lunes y miércoles por la tarde tienen una reunión por Google Hangouts para seleccionar las mejores ideas, que quedan apuntadas en un documento de texto que está en Dropbox, donde ya acumulan más de 50.000 titulares, aunque la mayoría son "malos", según García de la Riva. Por eso, la clave para escoger un buen titular está en que les haga gracia a ellos mismos.

De forma indirecta, los contenidos de El Mundo Today se rigen por los criterios de noticiabilidad, con la salvedad de que parten de la condición de ser información imaginada e inventada. Sin embargo, sí que tienen en cuenta la actualidad, la proximidad, la rareza, el suspense y la emoción, aunque no vayan enfocados a informar sino a entretener. La diferencia a la hora de elaborar las piezas radica en que en este diario se redactan titulares para luego crear los cuerpos a partir de la inventiva del redactor. Se piensan titulares susceptibles de provocar la risa a modo de gag, para después escribir el cuerpo con apariencia de noticia informativa. En la rutina periodística de un medio de comunicación, el titular se redacta tras conocerse el acontecimiento. El hecho de elaborar información falsa y principalmente el enfoque humorístico, hacen que el acontecimiento se cree a partir del titular y no a la inversa.

Además, los formatos que utilizan se basan en el tipo de contenidos que aparecen en los medios de comunicación. A través del citado grupo de Whatsapp, se comparten piezas periodísticas, tanto para estar pendientes de la actualidad como para seguir las narrativas y formatos que aparecen en los medios. El hecho de parodiar a medios informativos, les permite explorar en los contenidos que estos hacen. Sin embargo, la finalidad humorística hace que los contenidos sean pensados principalmente para perdurar en el tiempo, ya que el humor ha de ser un producto duradero mientras que la actualidad es perecedera.

Después de esas reuniones, los directores asignan a los redactores los textos seleccionados, para tener una programación clara durante la semana, y después cada redactor vuelca en Dropbox su futura publicación. Finalmente Puig Ripoll y García de la Riva repasan el texto para que no tenga errores a la hora de publicarlo en la web, lo suben al CMS (WordPress), se maqueta y se programa. "Después, lo difundimos en las redes sociales usando programas de socialmedia, que permiten programar tuits y publicaciones desde Facebook de forma escalonada y automática", matiza Puig Ripoll.

Si hay que modificar, corregir o actualizar una publicación, se coordinan de nuevo por WhatsApp o por teléfono si es urgente.

Con el tiempo y el consiguiente crecimiento del medio, se ha sistematizado en mayor medida el proceso de trabajo al haber más gente implicada. Cuando El Mundo Today abrió sus puertas no se hacían reuniones semanales ni se ponían los temas 
en agenda. A día de hoy, se ha pasado a hacer reuniones cada semana y a hacer una selección de la ingente cantidad de titulares que ponen en común.

\subsection{Modelo de negocio}

El Mundo Today opera como una comunidad de bienes, según el Código Civil, por lo que no están obligados a presentar cuentas. De hecho, no aparecen registrados en el Registro Mercantil, a pesar de que llevan más de diez años en activo. Tampoco tienen a nadie en nómina, ya que todos sus integrantes son colaboradores, al margen de los dos directores. Y la contabilidad y la gestión comercial la llevan por fuera, "igual que cualquier autónomo", reconocen los directores.

La iniciativa posee una cartera diversificada de fuentes de financiación que aseguran su sostenibilidad e independencia. Sus ingresos provienen de dos fuentes principales: la publicidad de mercado y la venta de trabajos por encargo (colaboraciones). En relación a la publicidad, recurre a los banners, display, eventos, contenido de marca y patrocinio. De hecho, la web del medio dispone de una tienda online donde el usuario puede adquirir de manera exclusiva, entre otros productos, la obra Historia, el libro (19 euros), que recopila 400 de las mejores efemérides publicadas durante los últimos años en El Mundo Today, dotándolas de un sentido cronológico y una estética compleja. También puede comprar tazas de café $(13,50$ euros), camisetas corporativas (19 euros), o bien con algún mensaje satírico (19 euros).

Los directores explican que son "un medio tradicional" en lo que a publicidad se refiere, aunque reconocen que "hay que hacer productos atractivos" para colocarlos "de forma orgánica y natural", a pesar de que el diario no se publicita en otros medios y soportes.

Las colaboraciones y trabajos con otros medios de comunicación también se han convertido en un pilar fundamental de su negocio. En prensa escrita, el diario colabora desde abril de 2016 en la sección de humor del suplemento dominical El País Semanal y, desde septiembre de ese mismo año, es colaborador fijo del suplemento de ocio On Barcelona, de El Periódico. También trabaja para el programa de televisión de humor y sátira de Cataluña Alguna pregunta més?, que se emite en TV3.

No obstante, estas no son las únicas colaboraciones, sino que a lo largo de sus diez años de andadura, también ha trabajado para otras compañías mediáticas. El 2009 colaboró con la productora audiovisual El Terrat, fundada por Andreu Buenafuente, y en 2010, con Prisa Radio, elaborando falsos boletines informativos semanales para Hoy por Hoy, de Cadena SER. Ese mismo año también realizó trabajos por encargo para Atrévete, el programa despertador de Cadena Dial y para Morning 80, de M80 Radio, actividad que mantuvo hasta julio de 2012. Igualmente ha colaborado en los programas La Ventana y A vivir que son dos días, de Cadena SER. En 2012 también trabajó para El País, redactando la última página del suplemento ocio ya desaparecido On Madrid. En 2015 inauguró una sección en el programa El último mono, de La Sexta, y comenzó a producir informativos semanales para Atresmedia, bajo el nombre El Mundo Today 24 horas. Ente 2015 y 2017 también colaboró en el programa de música y humor Oh! My LOL SON Estrella Galicia, de Cadena SER. Durante sus diez años de actividad, El Mundo Today también ha creado su propio espectáculo teatral, El Mundo Today Live, ha estrenado su propio noticiero en directo en los Cines Maldà de Barcelona y ha presentado diferentes galas de los Premios de 
la Música Independiente (Premios MIN), que organiza la Unión Fonográfica Independiente (UFI).

Estas colaboraciones demuestran que el diario no vive exclusivamente de la difusión de contenidos, sino de la marca que han construido en torno a ella. Los directores y colaboradores aprovechan su activa participación en redes sociales para proyectar su marca periodística personal ante miles de seguidores en el nuevo entorno comunicativo global. El perfil de El Mundo Today en redes sociales es visitado, comentado y compartido de forma recurrente (Gráficos 3 y 4). El uso intensivo que realizan de las redes sociales sirven para la promoción de los contenidos, el establecimiento de un canal de conversación con lectores y otras funciones similares, ya que los mensajes en las redes sociales se someten a un permanente escrutinio por parte de un elevado número de followers, entre los que se generan conversaciones multidireccionales.

Sin embargo, Puig Ripoll y García de la Riva no quieren involucrar a la comunidad que le sigue para conseguir más dinero, ya que consideran que "Internet es un entorno difícil y precario" y que "sólo la audiencia más fiel pagará por sus contenidos". Esta forma de generar ingresos también es conocida como crowdfunding (García Labarta, 2014, Lorca, 2010).

Los directivos y colaboradores son reticentes a la hora de aportar datos y cifras concretas que permitan discernir qué ingresos mensuales obtienen, aunque reconocen que generan el volumen necesario para cubrir costes y generar ahorros. En este sentido, Puig Ripoll afirma: “Te prometo que no sé cuánto gano. Tenemos una cuenta común para El Mundo Today, donde vamos metiendo todo y utilizándolo para los diferentes proyectos. Es verdad que hay más dinero que cuando empezamos, pero no he calculado cuánto gano al mes. Cuando nos hace falta alguna cantidad, lo vamos sacando de esa cuenta. Vivimos sin problemas del diario, pero no estamos forrados como piensa la gente". Por su parte, García de la Riva reconoce que no tienen un modelo de negocio concreto, ya que lo hacen todo de manera "muy artesana", y subraya que su estrategia para fortalecer la comunidad de usuarios es "ofrecer la mejor calidad en el contenido".

En un primer momento, el diario se financió con el dinero aportado por los dos directores, con la esperanza de darlo a conocer al gran público. No obstante, el crecimiento continuado de sus cuentas, y su capacidad para incrementarlas, demuestran la evolución futura de este proyecto, que sigue la estela del estadounidense The Onion, que "es un espejo en el que nos gusta mirarnos", cuenta Puig Ripoll. De hecho, su éxito continuado ha hecho que se creen proyectos similares, como la página Parece del Mundo Today, que recopila noticias de verdad que podrían ser de El Mundo Today.

En cuanto a sus perspectivas de futuro, los directivos no saben cómo evolucionará el diario en los próximos cinco años, ya que no hacen previsiones, pero confían en poder publicar más libros autoeditados, para establecer una relación comercial directa con nuestros lectores. "Hay que ir innovando y ofreciendo contenidos para que nuestro humor siga resultando fresco y efectivo en los próximos años", matiza García de la Riva. 


\section{Discusión y conclusiones}

La investigación desarrollada permite dar por conseguido el objetivo planteado inicialmente de analizar la estructura, composición y funcionamiento de El Mundo Today, así como sus procesos productivos y el impacto de su actividad para la empresa.

El diario nació como una startup basada en el humor y en los contenidos ficticios, cuyo objetivo era crear parodia y sátira. En el momento de su lanzamiento, estaba compuesta por dos personas, sus directores, aunque con el paso del tiempo ha sumado nueve colaboradores a su plantilla, que se definen por la multidisciplinariedad y complementación entre sus perfiles profesionales. En este sentido, el diario cuenta con editores de vídeo, guionistas de radio y televisión, desarrollo de audiencias, diseñador de experiencia de usuarios y especialistas en Photoshop. En relación a su metodología de trabajo, los integrantes de El Mundo Today hacen un uso intensivo de las tecnologías digitales e Internet, como las redes sociales y los servicios de alojamiento de archivos multiplataforma en la nube, ya que carecen de redacción física al uso. Se confirma, por tanto, la hipótesis 1, pues quedan respaldas las aportaciones sobre startup que realizan Ries (2011), Blank y Dorf, (2012), Pavlik (2013), De Lara González (2015), Rosique Cedillo y Barranquero Carretero (2015), Carlson y Usher (2016) y Montoya Pineda, (2016).

Pero el crecimiento potencial de la empresa (escalable, según Blank y Dorf, 2012) y su rentabilidad la han convertido en una compañía consolidada. El diario cuenta con un elevado número de seguidores y usuarios (recibe una media mensual de 250.000 visitas), y ha sabido adaptarse al mercado y encontrar diferentes vías para obtener beneficios y generar valor, como proponían Blank y Dorf, (2012). A la publicidad tradicional o display se suman los eventos, el contenido de marca, el patrocinio y la venta de trabajos por encargo (colaboraciones) a diferentes grupos de comunicación, como Prisa y Atresmedia, entre otros, que ha hecho que el proyecto sea sostenible y rentable. Estas fuentes de financiación se han conseguido, en parte, gracias a la mentalidad abierta e innovadora de sus directores, Xavi Puig Ripoll y Kike García de la Riva (Gynnild, 2013). En este sentido, se corrobora la hipótesis 2, ya que El Mundo Today posee una cartera diversificada de fuentes de financiación que aseguran su viabilidad e independencia, de acuerdo con lo que advertían Timmers (1998), Picard (2002), y Osterwalder, Pigneur y Tucci (2005). Sin embargo, no hay que olvidar que, según declaran los directivos del diario, no solo se persigue el beneficio individual, sino que, por medio de la búsqueda de un modelo que les ayude a generar y capturar valor, prestan atención a las demandas de las comunidades, que ven ciertas necesidades cubiertas.

Por todo lo expuesto, y entendiendo que el modelo de negocio es la forma en la que las empresas crean, distribuyen y capturan valor, según Carvajal (2015a), cabe afirmar que la importancia de El Mundo Today reside en el ofrecimiento de valores añadidos novedosos a unas audiencias con características diferentes. El caso estudiado responde al modelo de nueva iniciativa emprendedora (Manfredi; Rojas; Herranz, 2015), y refleja el cambio cultural y tecnológico que está atravesando la industria mediática (Pavlik, 2015).

Igualmente, es posible confirmar la tercera hipótesis, debido a que el objetivo de este diario no es desinformar, sino entretener y hacer un tipo de humor a través de la sátira sobre la actualidad nacional e internacional que perdure en el tiempo, como han declarado sus directores. 
No obstante, y a pesar de corroborar las tres hipótesis de partida, esta investigación también cuenta con ciertas limitaciones y deja abiertas posibilidades para futuras investigaciones. Una muestra más amplia habría posibilitado la extracción de más condiciones extrapolables a la totalidad del mercado, de la misma forma que la inclusión de iniciativas del ámbito internacional podría ayudar a comparar el desarrollo de estas iniciativas en España con los de otros países. Para futuros análisis, cabría también tener en cuenta casos de fracaso, además de los de éxito, para discernir las causas que determinan si una iniciativa va a tener éxito o no entre su público objetivo. No por ello, los resultados quedan invalidados, puesto que la finalidad primordial de este trabajo no es de carácter cuantitativo sino cualitativo. Es decir, no importa tanto el número como los argumentos que se emplean en el objeto de estudio.

\section{Referencias}

Allcott, H.; Gentzkow, M. (2017). "Social Media and Fake News in the 2016 Election". En Journal of Economic Perspectives, 31(2), pp. 211-236.

Aguado, G. (2016): "El modelo de negocio de las empresas informativas". En Empresa informativa XXI. Planificación estratégica. En Galán Gamero, J. (coord.) Madrid: Editorial Síntesis.

Balmas, M. (2012). "When Fake News Becomes Real. Combined Exposure to Multiple News Sources and Political Attitudes of Inefficacy, Alienation, and Cynicism". En Communication Research, v. 41, pp. 430-454.

Baumann, S. (2013). "Adapting to the brave new world: Innovative organisational strategies for media companies". En Storsul, T. y Krumsvik, A. H. (Eds.), Media Innovation. A Multidisciplinary Study of Change, pp. 77-92. Göteborg: Nordicom.

Benoît, D.; Lecocq, X. (2009). "Evolución de los modelos de negocio: hacia una visión de la estrategia en términos de coherencia dinámica". En Universia Business Review, Madrid, n. 23, pp. 86-107.

Berinsky, A. J. (2015). "Rumors and Health Care Reform: Experiments in Political Misinformation”. En British Journal of Political Science, 47(2), pp. 241-262.

Blank, S.; Dorf, B. (2012). The Startup Owner's Manual: The Step-by-step Guide for Building a Great Company. K\&S Ranch, Incorporated.

Boczkowski, P. (2016). "Las noticias falsas y el futuro del periodismo". En Infobae, el 13 de diciembre. Recuperado de: https://www.infobae.com/opinion/2016/12/13/las-noticias-falsas-y-el-futuro-del-periodismo/

Burkhardt, J. M. (2017). "Chapter 1. History of Fake News". En Library Technology Reports, 53(8), 5- 9 .

Cambridge Dictionary (2018). Significado de fake news. Recuperado de: https://dictionary. cambridge.org/es/diccionario/ingles/fake-news

Campos Freire, F. (2010a). "Las empresas de medios de comunicación revisan y amplían sus modelos de negocio". En Razón y Palabra, n. 74.

- (2010b). "Los nuevos modelos de gestión de las empresas mediáticas". En Estudios sobre el mensaje periodístico, n. 16, pp. 13-30.

Carlson, M.; Usher, N. (2016). "News Startups as Agents of Innovation: For-profit digital news startup manifestos as metajournalistic discourse”. En Digital Journalism, 4(5), pp. 563-581. 
Carvajal Prieto, M. (2015a). "Lean Startup y Design Thinking. Nuevos métodos para innovar en periodismo . En C. A. de Comunicación (Ed.), Innovación y Periodismo: emprender en la Universidad, pp. 47-56. La Laguna (Tenerife): Latina.

- (2015b). "Seis modelos de negocio para el periodismo en la era de las plataformas". Noticias y pistas del máster en Innovación en Periodismo. Recuperado de: http://mip.umh.es/ blog/2015/10/12/seis-modelos-negocio-periodismo-plataformas/

Casero Ripollés, A.; Cullell March, C. (2013). "Periodismo emprendedor. Estrategias para incentivar el autoempleo periodístico como modelo de negocio". En Estudios sobre el mensaje periodístico. v. 19, pp. 681-690.

Checa Godoy, A. (2016): "Auge y crisis de la prensa satírica española en el Sexenio Revolucionario (1868-1874)". En El Argonauta Español, Revue bilingue, francoespagnole consacrée à l'étude de la presse espagnole de ses origines à nos jours (XVII'-XXI' siècles), $\mathrm{n}^{\circ}$ 13. Recuperado en: http://argonauta.imageson.org/document $97 \mathrm{html}$

Chesbrough, H.; Rosenbloom, R. S. (2002). "The role of the business model in capturing value from innovation: evidence from Xerox Corporation's technology spin-off companies". Industrial \& Corporate Change 11, pp. 529-555.

Collins Dictionary (2018). Significado de fake news. Recuperado de: https://www.collinsdictionary.com/dictionary/english/fake-news.

De Lara González, A. (2015). “Organizarse para innovar en las redacciones”. En García Avilés, J. A.; J. L. Ferris, J. L.; González, J. L. (Eds.), Innovar en Periodismo, pp. 135-142. Elche: Diego Marín.

Domínguez Martín, E.; Pérez Colomé, J. (2014). Microperiodismos II: aventuras periodísticas digitales en tiempos de crisis. Barcelona: Editorial UOC.

Evangelista, J. (2014). "El modelo de negocio híbrido en la prensa digital. Hacia un estudio de caso de los diarios digitales: Noticias sin, Acento.Com y Z-101 Digital en la República Dominicana". En Razón y Palabra, n. 87.

Faustino, P.; Gonçalez, R. (2011). Gestão Estratégica e Modelos de Negócio. O caso da indústria de mídia. Lisboa: Media XXI/Formalpress.

Gaitán, J. A.; Piñuel, J. L. (1998). Técnicas de investigación en Comunicación Social. Madrid: Síntesis.

García Avilés, J. A; Carvajal, M.; Comín, M. (Ed.) (2016). Cómo innovar en periodismo. Entrevistas a 27 profesionales. Murcia: Librero Editor.

García Labarta, C. (2014). "Presente y futuro del crowdfunding como fuente de financiación de proyectos empresariales". En Revista Española de Capital Riesgo, 1, pp. 3-19.

García Santamaría, J. V. (Ed.) (2014). El negocio de la prensa digital. En busca de un modelo sostenible para los tiempos nuevos. La Rioja: Instituto para la innovación periodística. Logroño.

Giles, R.H. (2010). New economic models for U.S. journalism. Dedalus, pp. 26-38.

González Esteban, J. L. (2014). “La transformación del ecosistema mediático español: el caso de eldiario.es". En Revista Mediterránea de Comunicación, 5(2).

Goyanes Martínez, M. (2013). "Estrategias y modelos de negocio: aclaración de conceptos y terminología de la prensa en Internet”. En Estudios sobre el mensaje periodístico, v. 19, n. 1, pp. 419-431.

Gynnild, A. (2013). "Journalism innovation leads to innovation journalism: The impact of computational exploration on changing mindsets". En Journalism, 15(6), pp. 713-730.

Infoadex (2014). Estudio InfoAdex de la inversión publicitaria en España 2014. Madrid: Infoadex. Recuperado de: http://www.infoadex.es/resumen_estudio_2014.pdf

Jarvis, J. (2015). El fin de los medios de comunicación de masas. Barcelona: Gestión 2000. 
Khaldarova, I.; Pantti, M. (2016). "Fake News. The narrative battle over the Ukrainian conflicto". Journalism Practice, 12 de abril, v. 10, pp. 891-901.

Kirby, E. J. (2016). "La ciudad europea que hizo una fortuna a base de crear noticias falsas sobre las elecciones de Estados Unidos”. En BBC News. Recuperado de: https://www. bbc.com/mundo/noticias-38222222

Küng, L. (2015). Innovadores en Noticias Digitales. Innovadores en Noticias Digitales. Londres y Nueva York: IB Tauris \& Co. Ltd.

Laguna Platero, A. (2003). "El poder de la imagen y la imagen del poder: la trascendencia de la prensa satírica en la comunicación social”. En IC Revista Científica de Información y Comunicación, 1, p. 111-132.

Laguna Platero, A.; Martínez Gallego, F. A. (2015). "Imaginarios femeninos a través de la prensa satírica: de Gil Blas a Don Quijote (1864-1902)". En Revista de la Asociación Española de Investigación de la Comunicación, v. 2, n. 3, pp. 49-63.

Llera, J. A. (2003). "Una historia abreviada de la prensa satírica en España: desde 'El Duende Crítico de Madrid' hasta 'Gedeón'”. En Estudios sobre el mensaje periodístico, (9), pp. 203-214.

Lorca, G. (2010). El Crowdfunding y los nuevos modelos de negocio info-digital. I Congreso Internacional de Comunicación Audiovisual y Publicidad. Internet y la información, pp. 79-98.

Manfredi Sánchez, J. L. (2015). Innovación y Periodismo: emprender en la Universidad. Cuadernos Artesanos de Comunicación. La Laguna (Tenerife): Latina.

Manfredi Sánchez, J. L.; Rojas Torrijos, J. L.; Herranz De La Casa, J. M. (2015). "Innovación en el periodismo emprendedor deportivo. Modelo de negocio y narrativas". En El profesional de la información, v. 24, n. 3, pp. 265-273.

Montoya Pineda, D. M. (2016). "Startup y Spinoff: definiciones, diferencias y potencialidades en el marco de la economía del comportamiento". En Contexto, (5), pp. 141-152.

Navas López, J. E.; Guerras Martín, L. A. (2007). La dirección estratégica de la empresa. Teoría y aplicaciones. Thomson Civitas, Madrid.

Osterwalder, A.; Pigneur, Y.; Tucci, C. L. (2005). "Clarifying business models: Origins, present, and future of the concept". En Communications of the Association for Information Systems, 16, pp. 1-25.

Pavlik, J. V. (2013). "Innovation and the Future of Journalism". En Digital Journalism, 1(2), pp. 181-193.

Picard, R.G. (2002). The economics and financing of media companies. Nueva York: Fordham University Press.

- (2010). Value creation and the future of news organizations. Lisboa: Media XXI.

Ries, E. (2011). The Lean Startup: How Today's Entrepreneurs Use Continuous Innovation to Create Radically Successful Businesses. New York: Crown Publishers.

Román, C. (2010). "De la sátira impresa a la prensa satírica. Hojas sueltas y periódicas en la configuración de un imaginario político para el Río de la Plata (1779-1834)". En Estudios 18:36, julio-diciembre. pp. 324-349.

Rosique Cedillo, G.; Barranquero Carretero, A. (2015). "Periodismo lento (slow journalism) en la era de la inmediatez. Experiencias en Iberoamérica". En El Profesional de la Información, 24(4), pp. 451-462.

Rubin, V. L.; Chen, Y.; Conroy, N. J. (2015). "Deception detection for news: Three types of fakes". En Proceedings of the Association for Information Science and Technology, 52(1), $1-4$.

Rubio Hancock, J. (2018). “Así son los ‘El Mundo Today’ de Europa”. En El País, 23 de julio. Recuperado de: https:/elpais.com/elpais/2018/06/26/actualidad/1530021798_561952.html 
Soler Pujal, P.; Enríquez Jiménez, A. M. (2012). "Reflexión sobre el rigor científico en la investigación cualitativa". En Estudios sobre el Mensaje Periodístico 18, pp. 879-888.

Tandoc, E. C.; Lim, Z. W.; Ling, R. (2018). “Defining 'Fake News': a typology of scholarly definitions”. En Digital Journalism, 6(2), pp. 137-153.

Timmers, P. (1998). "Business Models for Electronic Markets”. En Electronic Markets, 8(2). Recuperado de: http://www.cs.uu.nl/docs/vakken/ec/Timmers_BMem.pdf

Valero Pastor, J. M.; González Alba, J. A. (2018). "Las startups periodísticas como ejemplos de innovación en el mercado mediático español. Estudio de casos". En Revista Latina de Comunicación Social, 73, pp. 556-582.

Wilkilson, J.W. (2017). "El más que rancio abolengo de las 'fake news". La Vanguardia, 9 de diciembre. Recuperado de: http:/www.lavanguardia.com/cultura/20171209/433492087454/oliver-cromwell-fake-news-jamaica-postverdad-espana. html 